\title{
Biotechnology's long-term promise
}

\author{
Despite market perturbations, the industry's power to deliver \\ real value is growing.
}

\author{
Carl B. Feldbaum
}

Conventional wisdom has it that investing in biotechnology should be considered more risky than investments in other industries. I think this is a short-term view and does not take into consideration the relative challenges. The reason this opinion is now circulating is that the work of biotechnology companies is complex and not well understood on Main Street or on Wall Street. The fact that these companies are taking on challenges few would ever dream of and producing results is rarely factored into this risk analysis. These innovators are developing new therapies and cures for the most intractable and deadly illnesses. They are inventing diagnostic tests that enhance disease prevention. They are improving agriculture. They are cleaning up the environment. They are redesigning industrial manufacturing processes. In short, they are changing the world as no innovative industry ever has, which, of course, can translate into longterm substantial rewards.

\section{Understanding the risk}

Certain investors have recognized this riskto-reward ratio and have gained great advantage from it. Two stock market indices, the NASDAQ Biotech Index and the American Stock Exchange (AMEX) Biotech Index, add weight to the notion that the biotechnology sector is sound in the long run. For example, despite the ups and downs of all high-technology sectors between January 1995 and the late fall of 1997, the NASDAQ Biotech Index climbed steadily. The AMEX Biotech Index also rose and continued gaining into the first part of 1998 . Both these indices "headed south" as 1998 progressed. But biotechnology was not alone in this trend. Economic crises outside the US created instability in markets around the world from Hong Kong to Tokyo to London to New York. Political scandals in Washington did not help the situation.

Carl B. Feldbaum is president of the Biotechnology Industry Organization, 1625 K. Street NW, Suite 1100, Washington, DC 20006 (cfeldbaum@bio.org).
Toward the end of 1998, alarming perturbations in the markets undermined confidence in risk-to-reward ratios for virtually all stocks. The perception of risk simply overwhelmed all anticipation of long-term rewards. Specifically, what happened to the biotech sector? Financial experts said frightened investors sought refuge in bonds, other financial instruments, and stocks of large capitalization, cash-rich companies to weather the storm instead of those of smaller capitalized firms - a category defining the majority of biotechnology companies. The 1998 storm packed hurricane-force winds.

Ironically, this market uncertainty hit just at the time when the biotechnology industry is moving from trading on hopes and promises to trading on performance and new products. This is a time when the inherent, long-term value of companies engaged in the biotechnology revolution has never been more evident: More than 65 biotechnology drugs are already on the market helping more than 100 million people. Nearly 300 more drugs are now in human clinical trials and hundreds more are in preclinical studies. Hundreds of new medical diagnostic tests are available, making earlier disease detection possible. Millions of acres of biotechnology crops were harvested in 1998, improving food characteristics such as taste and nutritional value. Environmental biotechnology products are cleaning up hazardous wastes more safely and efficiently. Industrial biotechnology products - such as enzymes, which replace phosphates in laundry detergents-are reducing wastes, pollution, and energy consumption.

\section{Positive indicators}

With the biotech industry's fast-developing knowledge of genomics, discoveries about human health and the environment are made daily. Those discoveries have commercial applications over a broad range of industries, not just the pharmaceutical sector. Maturation of the biotechnology industry, where promises of new products now have a real track record, is not the sole reason for enthusiasm.

Pharmaceutical companies have bet their futures-the success of their product pipelines-on biotechnology. Over the past five years, pharmaceutical companies pledged $\$ 13$ billion in more than 750 collaborations with biotechnology companies. Those totals do not include deals in which financial terms were not disclosed. Major pharmaceutical companies continue to exhibit confidence in biotechnology. The number of alliances soared 220\% from 1993 to 1997 . During those years, investments in biotechnology by pharmaceutical firms skyrocketed from $\$ 1.4$ billion in 1993 to $\$ 4.4$ billion in 1997.

Another reason for enthusiasm in the biotechnology industry is the adoption in 1997 of the US Food and Drug Administration Modernization Act. This legislation represents the first reform in decades and is designed to streamline the FDA review process to approve biotech drugs faster and get them to patients sooner.

Yet another positive indicator of biotechnology's health is US federal funding for basic research, which fuels future commercial growth. Congress has been aggressive in funding research, appropriating $\$ 15.6$ billion for the US National Institutes of Health in FY 1999, a more than $14 \%$ increase over FY 1998. That support, from both Republicans and Democrats, shows no signs of abating. In fact, some Republicans have been more supportive than President Clinton, suggesting that appropriations should be doubled over the next five years.

\section{Conclusions}

The biotechnology revolution remains vibrant and robust. By November 1998, both the NASDAQ and AMEX biotech indices were making dramatic recoveries from their declines during the summer and early fall. Public demand for new therapies and cures is one of many powerful motivations for continued investment in this sector. Market shake-ups are troubling, but they provide an occasion to pause and reflect on what is at stake in the biotechnology revolution. They also serve to remind investors of the opportunities inherent in the longer-term development of biotechnology companies. /// 